\title{
Diagnostic performance of cytology for assessment of hepatic lipid content in dairy cattle
}

\author{
M. M. Fry, ${ }^{*}$ B. Yao,† C. Ríos,ł C. Wong,† S. Mann,† J. A. A. McArt,† D. V. Nydam,† F. A. Leal Yepes,§ \\ L. Viesselmann, ${ }^{*}$ A. Geick,\# K. Goldin,\# A. Jordan,\# and E. Behling-Kelly ${ }^{1}$ \\ *Department of Biomedical and Diagnostic Sciences, University of Tennessee, Knoxville 37996 \\ †Department of Population Medicine and Diagnostic Sciences, Cornell University, Ithaca, NY 14853 \\ ‡Dirección Académica, Universidad Santo Tomás, Mendoza 120, Los Ángeles, Chile \\ $\S$ Department of Animal Science, Cornell University, Ithaca NY 14853 \\ \#College of Veterinary Medicine, University of Tennessee, Knoxville 37996
}

\section{ABSTRACT}

The objective of our study was to characterize the diagnostic performance of cytology for assessing hepatic lipid content (HLC) in dairy cows by comparing microscopic evaluation of lipid vacuolation in touch imprint slide preparations of liver biopsies with quantitative measurement of triglyceride concentration ([TG]; mg/ $\mathrm{mg}$ of wet weight) in paired biopsy samples. Our study also sought to compare the diagnostic performance of liver cytology, plasma nonesterified fatty acid concentration ([NEFA]), and plasma $\beta$-hydroxybutyrate concentration $([\mathrm{BHB}])$ derived from a measurement performed on whole blood, for assessing HLC. Chemical extraction of TG from liver tissue remains the gold standard for quantifying HLC, largely because available blood tests, although useful for detecting some types of pathology, such as increased lipid mobilization, ketosis, or hepatocellular injury, are nonspecific as to etiology. Veterinary practitioners can sample bovine liver for cytological evaluation in a fast, minimally invasive, and inexpensive manner. Thus, if highly predictive of HLC, cytology would be a practical diagnostic tool for dairy veterinarians. In our study, liver biopsy samples from Holstein cows (219 samples from 105 cows: 52 from cows 2 to $20 \mathrm{~d}$ prepartum, 105 from cows 0 to $10 \mathrm{~d}$ in milk, 62 from cows 18 to $25 \mathrm{~d}$ in milk) were used to prepare cytology slides and to quantify [TG] using the Folch extraction method followed by the Hantzch condensation reaction and spectrophotometric measurement. An ordinal scale (0-4) based on amount of hepatocellular cytoplasm occupied by discrete clear vacuoles was used by 3 blinded, independent observers to rank HLC in Wright-Giemsa-stained slides. Interobserver agreement

Received March 20, 2017.

Accepted October 10, 2017.

${ }^{1}$ Corresponding author: eb58@cornell.edu in cytology scoring was good. Corresponding plasma [NEFA] and [BHB] measurements were available for 187 and 195 of the 219 samples, respectively. Liver [TG] correlated more strongly with cytology score than with NEFA or BHB, and receiver operating characteristic curve analysis showed that cytology had better diagnostic performance than either NEFA or BHB for correctly categorizing [TG] at thresholds of 5, 10, and $15 \%$. Hepatic lipidosis in high-producing dairy cows is of major clinical and economic importance, and this study demonstrates that cytology is an accurate means of assessing HLC. Additional work is indicated to evaluate the diagnostic utility of liver cytology.

Key words: $\beta$-hydroxybutyrate (BHB), cytology, lipidosis, liver, nonesterified fatty acids (NEFA)

\section{INTRODUCTION}

Hepatic lipidosis (HL, also known as fatty liver) is a clinical syndrome that occurs in dairy cattle with excessive accumulation of lipids, specifically triglycerides (TG), in hepatocytes. Clinical HL develops secondary to severe negative energy balance, most commonly in high-producing cows in early lactation, when mobilization of fat stores results in increased delivery of nonesterified fatty acids (NEFA) via the bloodstream to the liver, which is unable to oxidize or export TG in lipoproteins at an equivalent rate (Herdt, 1988; Bobe et al., 2004). Subclinical forms of HL occur, and some degree of TG accumulation in the liver occurs in most postpartum dairy cows. Although some degree of increased hepatic TG is not necessarily pathologic, the syndrome of HL is characterized by excessive TG accumulation and clinical illness of varying severity, from common postpartum diseases and poor response to therapy (Herdt, 1988). Clinical abnormalities associated with HL in dairy cattle - including metritis, mastitis, ketosis, abomasal displacement, and decreased reproductive performance - result in decreased productivity 
and major economic losses; annual costs of fatty liver in dairy cows in the United States have been estimated to be more than $\$ 60$ million (Bobe et al., 2004; McArt et al., 2012).

At present, there is no reliably accurate blood test, or combination of tests, to quantify hepatic lipid content (HLC) or diagnose HL in cattle (Herdt, 1988; Cebra et al., 1997; Kalaitzakis et al., 2007). Hepatic lipid content can be measured definitively by chemical methods and can be estimated in various ways, such as histologically using lipid-soluble stains (Gaal et al., 1983), by flotation of biopsy specimens in copper sulfate solutions of different specific gravities, or ultrasonographically (Bobe et al., 2008; Starke et al., 2010; Haudum et al., 2011). In addition, papers dating back more than 50 years describe the use of fine-needle biopsy (FNB) and cytologic examination to detect hepatic lipid accumulation in cattle (Holtenius, 1961; Holtenius et al., 1962; Hoff and Cote, 1996). More recently, a study conducted by part of our research team using fresh bovine liver samples obtained at slaughter found moderate correlation between rank scoring of lipid vacuolation cytologically and histologically (Ríos et al., 2010, 2013). Lipid content was estimated to be higher by cytologic evaluation than by histologic evaluation, suggesting that cytology might be the more sensitive of the 2 methods for assessing HL. Those findings led us to hypothesize that microscopic assessment of lipid accumulation in cytological preparations accurately predicts liver TG content in dairy cows.

The main objective of our study was to characterize the diagnostic performance of cytology for assessing HLC in dairy cattle, using TG concentration ([TG]; $\mathrm{mg} / \mathrm{mg}$ of wet weight) in paired liver samples as the reference method. Our study also sought to compare diagnostic performance of cytology with that of plasma [NEFA] and [BHB]. If shown to be a valid means of assessing HLC in cattle, FNB cytology could be a valuable part of the routine diagnostic repertoire of the practicing dairy veterinarian.

\section{MATERIALS AND METHODS}

\section{Sample Acquisition}

Liver biopsies and blood samples were obtained from multiparous Holstein cows $(\mathrm{n}=105)$ enrolled in 2 separate studies conducted at the Cornell University Research Center (Ithaca, NY). Cows were between $20 \mathrm{~d}$ prepartum and 28 DIM. Tissue and blood was collected at between 1 and 3 time points per cow, corresponding to 20 to $2 \mathrm{~d}$ prepartum, 0 to 10 DIM, and 18 to 25 DIM. All samples were obtained following guidelines and pro- tocols approved by the Cornell University Institutional Animal Care and Use Committee (protocols 2013-0064 and 2015-0097). Cows were kept in sawdust-bedded tiestalls with ad libitum access to food and water. Cows were exercised 3 times per week during the dry period.

Liver biopsies were obtained by 1 of 2 clinical veterinarians via percutaneous trocar approach that incorporates an O-ring near the base of the cannula (Hughes, 1962; Veenhuizen et al., 1991). Hair was clipped from the 9 th intercostal space to the center of the paralumbar fossa, and the clipped area was washed with iodine soap and dried with paper towels. The biopsy site in the right 11th intercostal space was chosen after confirmation of correct placement with ultrasonography using a 7.5-MHz linear-array transducer (Ibex Pro, E.I. Medical Imaging, Loveland, CO) and 70\% ethanol (Vet One, Boise, ID) as a coupling agent to visualize the area where the liver was found immediately adjacent to the peritoneum. Following surgical preparation of the site, the overlying skin and underlying intercostal muscle tissue was infiltrated with $10 \mathrm{~mL}$ of a $2 \%$ lidocaine solution (lidocaine $2 \% \mathrm{HCl}$; Vet One). An approximately 1 -cm skin incision at the 11th intercostal space was made using a \#22 scalpel blade to place the stainless steel trocar $(31 \mathrm{~cm}$ long and $7.5 \mathrm{~mm}$ in diameter, Figure 1) into the abdominal cavity, directing the point of the trocar toward the left elbow. Tissue samples were placed on a $7.62-\times 7.62-\mathrm{cm}$ sterile nonwoven sponge to remove excess blood and used immediately to prepare cytology slides or snap-frozen in liquid nitrogen and stored at $-80^{\circ} \mathrm{C}$ until later measurement of [TG]. The incision was closed with a disposable skin stapler (3M Precise, St. Paul, MN) and coated with aluminum spray bandage. Samples were successfully collected at each attempt.

Blood samples were collected from the coccygeal vessels using a 20-gauge, 2.54-cm needle and blood collection tubes containing sodium heparin (158 USP units; Becton, Dickinson and Co., Franklin Lakes, NJ). Plasma was separated within $1 \mathrm{~h}$ by centrifugation at $3,000 \times g$ for $20 \mathrm{~min}$ at $4^{\circ} \mathrm{C}$ and stored at $-20^{\circ} \mathrm{C}$ until further analysis.

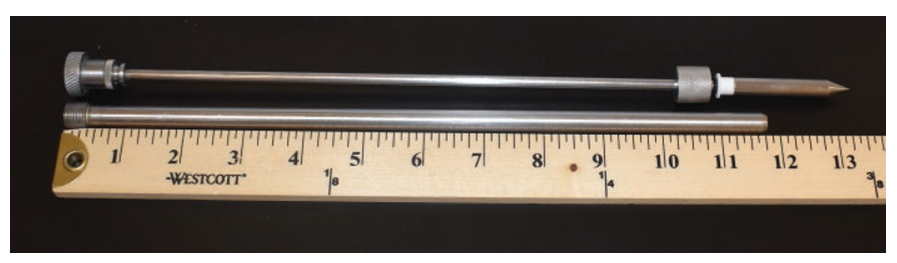

Figure 1. Photograph of the trocar device used to obtain biopsy samples. Ruler shown is in inches. Color version available online. 
Table 1. Ordinal scoring system for cytologic evaluation of hepatic lipid content

\begin{tabular}{ll}
\hline Score & Criteria \\
\hline 0 & No or very rare hepatocytes have any lipid vacuoles \\
1 & $<50 \%$ of hepatocytes have lipid vacuoles, or $>50 \%$ have vacuoles but estimated mean amount of cytoplasm affected in those cells \\
& is $<10 \%$ \\
3 & $>50 \%$ of hepatocytes have lipid vacuoles and estimated mean amount of cytoplasm affected in those cells is 10 to $50 \%$ \\
3 & $>50 \%$ of hepatocytes have lipid vacuoles and estimated mean amount of cytoplasm affected in those cells is 50 to $80 \%$ \\
\hline
\end{tabular}

\section{Slide Preparation and Cytology Scoring}

Cytology slides were prepared by making multiple imprints of liver tissue samples after removal of excess blood; imprinted slides were allowed to air dry and stored at room temperature until they were stained with Wright-Giemsa. Then, HLC was evaluated microscopically using a novel ordinal scale (Table 1 and Figure 2) based on estimated percentage of hepatocytes with discrete cytoplasmic vacuolation and estimated mean percentage of cytoplasm occupied by vacuoles on Wright-Giemsa-stained imprints (Hematek stainer, Siemens, Malvern, PA]. Three people - a board-certified clinical pathologist (MMF), a veterinarian with advanced clinical pathology training $(\mathrm{CR})$, and a clinical pathology resident (LV) - independently scored all of the cytology slides. Each evaluator was blinded to the other evaluators' scores, to the corresponding [TG], and to all other case information except for a slide identification number. Afterward, 3 veterinary students who had no prior cytology experience performed blinded, independent scoring of a subset of 50 slides representing a cross-section of rank scores as determined by the initial (experienced) evaluators; the inexperienced evaluators first received a brief (approximately $20 \mathrm{~min}$ ) orientation during which they reviewed representative photomicrograph images and glass slides of samples previously scored unanimously by the experienced observers.

\section{Measurement of Liver [TG]}

The [TG] of lipid extracts was measured via the Hantzsch condensation method and compared with a triolein standard curve (Folch et al., 1957). All reagents for the liver TG extraction were purchased from SigmaAldrich (St. Louis, MO). The saponification reagent (5\% $\mathrm{KOH}$ in 40:60 vol/vol isopropyl alcohol/water) was made by dissolving $5 \mathrm{~g}$ of KOH (P5958, Sigma-Aldrich) in $60 \mathrm{~mL}$ of distilled water and $40 \mathrm{~mL}$ of isopropyl alcohol (W292907, Sigma-Aldrich). Sodium metaperiodate reagent (SMR) was made by dissolving $77 \mathrm{~g}$ of ammonium acetate (09689, Sigma-Aldrich) in $700 \mathrm{~mL}$ of distilled water, to which $60 \mathrm{~mL}$ of acetic acid (27225, Sigma-Aldrich) and $650 \mathrm{mg}$ of sodium metaperiodate (31448, Sigma-Aldrich) was added before bringing the total volume of the solution to $1 \mathrm{~L}$ by addition of distilled water. Acetylacetone reagent was made by adding $0.75 \mathrm{~mL}$ of 2,4-pentanedione or acetylacetone (P7754, Sigma-Aldrich) to $20 \mathrm{~mL}$ of isopropyl alcohol and 80 $\mathrm{mL}$ of distilled water. Aluminum oxide (199974, SigmaAldrich) was washed 3 times with $75 \mathrm{~mL}$ of distilled water using Whatman filter paper and allowed to dry overnight. Chloroform:methanol (2:1 vol/vol) solution
A

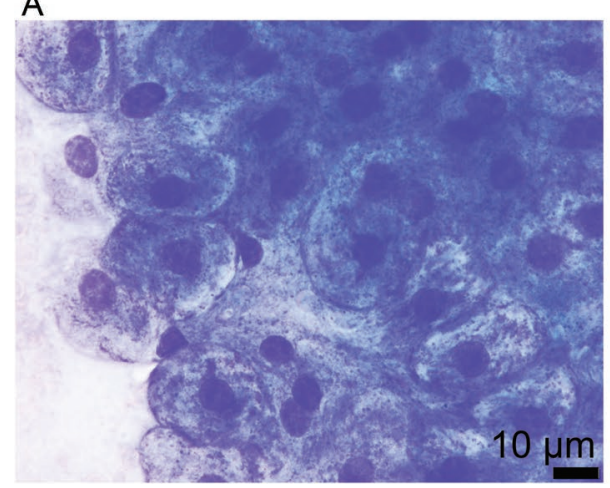

B

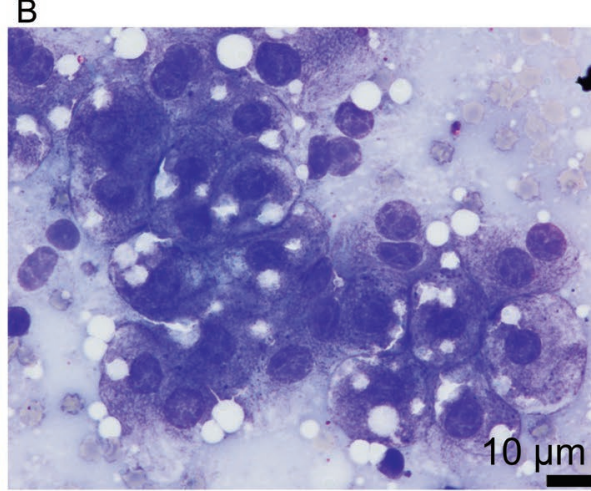

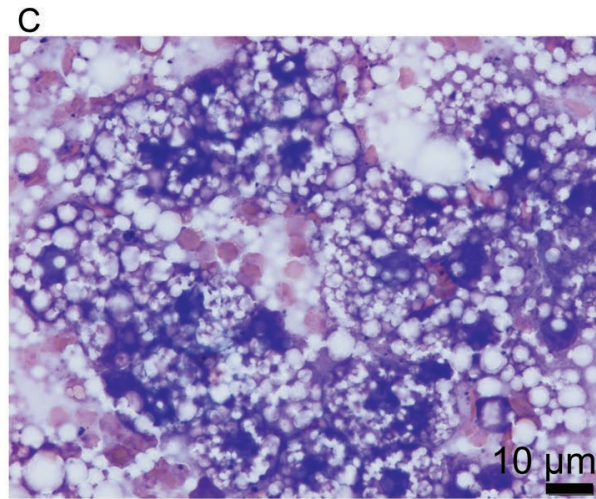

Figure 2. Photomicrographs of cases (stained with Wright-Giemsa) unanimously scored as "0" (A), "2" (B), or "4" (C) using the ordinal scale described in Table 1. Color version available online. 
Table 2. Triglyceride quantification intra- and interassay variability

\begin{tabular}{lcccccccc}
\hline \multirow{2}{*}{$\begin{array}{l}\text { Lipid infiltrate } \\
\text { in sample }\end{array}$} & \multicolumn{3}{c}{ Intraassay replicates $(\mathrm{n}=20)$} & & \multicolumn{3}{c}{ Interassay replicates $(\mathrm{n}=9)$} \\
\cline { 2 - 3 } \cline { 7 - 9 } & Mean & $\mathrm{SD}$ & $\mathrm{CV}$ & & Mean & $\mathrm{SD}$ & $\mathrm{CV}$ \\
\hline Minimal & 0.38 & 0.11 & 0.31 & & $\mathrm{ND}^{2}$ & $\mathrm{ND}$ & $\mathrm{ND}$ \\
Mild & 3.66 & 0.66 & 0.18 & & 3.67 & 0.75 & 0.20 \\
Marked & 16.09 & 1.30 & 0.081 & & 15.69 & 1.02 & 0.06 \\
\hline
\end{tabular}

${ }^{1}$ By gross assessment of the tissue.

${ }^{2} \mathrm{ND}=$ not done

was made using $50 \mathrm{~mL}$ of chloroform (372978, SigmaAldrich) and $25 \mathrm{~mL}$ of methanol (322415, Sigma-Aldrich). Triglyceride standard stock solution was made by dissolving $0.24 \mathrm{~g}$ of triolein (T7140, Sigma-Aldrich) in $80 \mathrm{~mL}$ of isopropyl alcohol, yielding a stock solution of $3,000 \mu \mathrm{g} / \mathrm{mL}$ triolein. Liver sample weights were determined and recorded before samples were placed in $0.5 \mathrm{~mL}$ of $2: 1$ ( $\mathrm{vol} / \mathrm{vol}$ ) chloroform:methanol extraction solvent (Folch et al., 1957). The samples were homogenized using a Polytron homogenizer (Polytron Corp., Montreal, Canada) on a setting of 7 for approximately $15 \mathrm{~s}$ or until the disappearance of visible chunks. The Polytron probe was rinsed with the following sequence of solutions: isopropyl alcohol, distilled water, ethanol (200 proof), and 2:1 (vol/vol) chloroform:methanol, between all samples to prevent cross-contamination. The homogenized samples were vortexed for $40 \mathrm{~min}$ at 1,278 $\times g$, followed by addition of $0.6 \mathrm{~mL}$ of distilled water. The sample was vortexed for an additional $40 \mathrm{~min}$ at $1,278 \times g$. The sample mixture was then centrifuged at $2,500 \times g$ for $1 \mathrm{~min}$. Then, $100 \mu \mathrm{L}$ of the bottom phase was added to $15-\mathrm{mL}$ conical tubes containing $0.4 \mathrm{~g}$ of dried aluminum oxide and $4 \mathrm{~mL}$ of isopropyl alcohol. The samples were shaken by hand for $5 \mathrm{~min}$ and centrifuged at $887 \times g$ for $10 \mathrm{~min}$. Triglyceride standards were prepared by serial diluting the $3,000 \mu \mathrm{g} / \mathrm{mL}$ stock solution of triolein with isopropyl alcohol to a final volume of $1 \mathrm{~mL}$ in $13-\times 100-\mathrm{mm}$ borosilicate glass tubes. One milliliter of each sample was then transferred to a new glass tube and $300 \mu \mathrm{L}$ of saponification reagent added to each sample and standard followed by vortex- ing for $3 \mathrm{~s}$ at $1,035 \times g$, incubation at $65^{\circ} \mathrm{C}$ for $15 \mathrm{~min}$, and then immersion in cold water for $5 \mathrm{~min}$. Next, 500 $\mu \mathrm{L}$ of SMR was added and the sample vortexed for $3 \mathrm{~s}$ at $1,035 \times g$. After SMR was added and vortexed, 250 $\mu \mathrm{L}$ of acetylacetone reagent was added and the sample was again vortexed for $3 \mathrm{~s}$ at $1,035 \times g$. The solutions were incubated for a second time at $65^{\circ} \mathrm{C}$ for $15 \mathrm{~min}$ and then cooled in iced water for $5 \mathrm{~min}$. The finished solution was pipetted in triplicates of $150 \mu \mathrm{L}$ into a 96-well plate, and the optical density of the solution was determined by measuring the absorbance of the sample at $405 \mathrm{~nm}$ (SpectraMax 3 and SoftMax Pro 6, Molecular Devices LLC, Sunnyvale, CA). The [TG] was expressed as a percentage based on milligrams per milligram of wet weight. Store-purchased bovine liver and samples collected at necropsy from animals with grossly lipid-infiltrated livers were used to determine intra- and interassay variability. Each of the 3 liver samples were measured 10 times in one assay to determine intraassay variability, and the 2 grossly affected samples were included with each batch $(\mathrm{n}=9)$

\section{Measurement of Plasma [NEFA] and [BHB]}

Plasma [BHB] was measured immediately after blood collection using a cow-side test, BHB TaiDoc ketone meter system (Pharmadoc, Lüdersdorf, Germany), before samples were placed on ice. The use of this handheld BHB meter was previously validated for use with bovine whole-blood samples (Bach et al., 2016). Plasma [NEFA] was measured using a previously validated en-

Table 3. Breakdown by liver triglyceride concentration [TG] for 219 cases from 105 multiparous cows

\begin{tabular}{|c|c|c|c|}
\hline \multirow[b]{2}{*}[\mathrm{TG}]{} & \multicolumn{3}{|c|}{ Number of cases ( $\%$ of group) } \\
\hline & 2 to $20 \mathrm{~d}$ prepartum & 0 to 10 DIM & 18 to $25 \mathrm{DIM}$ \\
\hline $\begin{array}{l}<5 \% \\
5 \% \leq[\mathrm{TG}]<10 \% \\
10 \% \leq[\mathrm{TG}]<15 \% \\
15 \% \leq[\mathrm{TG}]<20 \% \\
\geq 20 \% \\
\text { Subtotal per group }\end{array}$ & $\begin{aligned} & 52(100) \\
& 0(0) \\
& 0(0) \\
& 0(0) \\
& 0(0) \\
& 52\end{aligned}$ & $\begin{aligned} 28 & (27) \\
36 & (34) \\
8 & (8) \\
10 & (10) \\
23 & (22) \\
105 & \end{aligned}$ & $\begin{aligned} 2 & (34) \\
20 & (32) \\
8 & (13) \\
6 & (10) \\
7 & (11) \\
62 & \end{aligned}$ \\
\hline
\end{tabular}


zymatic reaction and colorimetric endpoint [HR Series NEFA-HR (2); Wako Life Sciences, Mountain View, $\mathrm{CA}]$ as previously described (Mann et al., 2015).

\section{Statistical Analyses}

Statistical analyses were performed using commercial software (Medcalc version 16.4.3, 64 bit; Medcalc, Ostend, Belgium). Interobserver agreement of cytology scoring was assessed by weighted kappa $(\mathbf{K w})$. Additional analyses were performed on data stratified by stage of lactation (2 to $20 \mathrm{~d}$ prepartum, 0-10 DIM, 18-25 DIM).

Triglyceride concentrations were assessed for normality by the D'Agostino-Pearson test. Correlation of [TG] results with median cytology score, plasma [NEFA], and plasma $[\mathrm{BHB}]$ was determined by Spearman's rank correlation $(\rho)$.

Diagnostic performance of cytology scoring, plasma [NEFA], and plasma [BHB] for assessing $[\mathrm{TG}]$ was characterized by receiver operating characteristic (ROC) curve analysis, using MedCalc's "Comparison of ROC curves" function. We categorized cases based on the conventional criterion of [TG], using 3 threshold values representing different severity of disease $(\geq 5, \geq 10$, and $\geq 15 \%$; to accommodate for rounding, the actual values used were $\geq 4.96 \%, \geq 9.96 \%$, and $\geq 14.96 \%$ ). This approach allowed for direct comparisons of cytology scoring, plasma [NEFA], and plasma $[\mathrm{BHB}]$ at each $[\mathrm{TG}]$ threshold.

\section{RESULTS}

Early in the study, 3 cows developed a pneumothorax, which clinically manifested as an immediate mild difficulty breathing secondary to the biopsy procedure. All 3 cows recovered without intervention. Intra- and interassay variability of the [TG] extraction and quantification method was low (Table 2). Cytology slides and [TG] measurements were available for 222 cases from 105 cows; of these, 3 cases were excluded before analysis. Two slides were excluded because of concern that samples had been misidentified; one slide was excluded because the specimen consisted predominantly of necrotic material, characterized by granular, amorphous, basophilic debris. A mild inflammatory infiltrate was sporadically noted, but analysis of this parameter was not included in the current study. After exclusion of those cases, 219 cases from 105 cows remained. Of these cases, 52 were from cows 2 to $20 \mathrm{~d}$ prepartum, 105 from cows 0 to 10 DIM, and 62 from cows 18 to 25 DIM. Corresponding plasma $[\mathrm{NEFA}]$ measurements were available for 187 cases from 99 cows, and corresponding plasma [BHB] measurements for 195 cases from 104 cows. Complete data (mean values for cytology score, [TG], and plasma [NEFA] and [BHB]) was available for 184 cases from 98 cows.

Cases represented a spectrum of disease severity based on [TG] (Table 3). Triglyceride concentration data were not normally distributed in any group (cows 2 to $20 \mathrm{~d}$ prepartum, 0 to $10 \mathrm{DIM}$, or 18 to $25 \mathrm{DIM}$ ).

Interobserver agreement for cytology scoring was $>0.65(\mathrm{Kw}=0.66$ to 0.79$)$ for all comparisons (Table 4). Cytology score had a higher correlation with [TG] than did plasma [NEFA] or [BHB] in all 3 cow groups (Figure 3). Correlation of [TG] and median cytology scores by inexperienced observers was close to that of the experienced observers $(\rho=0.92)$. Cytology score performed better than did plasma [NEFA] or [BHB] based on ROC curve analysis at different [TG] thresholds in the 0 to 10 DIM and 18 to 25 DIM cow groups (Table 5). A similar comparison could not be performed in the prepartum group because all cows had $[\mathrm{TG}]<5 \%$.

\section{DISCUSSION}

Cytology is used routinely to diagnose HL in companion animals, using Wright-Giemsa or other aqueous stains that are physically excluded from lipid droplet (Arndt and Shelly, 2014; Barger and MacNeill, 2016; Meyer, 2016). The potential for cytologically diagnosing HL in dairy cattle has been recognized for many decades (Holtenius, 1961; Holtenius et al., 1962; Hoff and Cote, 1996). Until the present investigation, however, published studies evaluating the diagnostic accuracy of cytology compared with an established reference meth-

Table 4. Interobserver agreement of cytology scoring by experienced observers for all cases $(\mathrm{n}=219)$ and by inexperienced observers for a subset of 50 cases

\begin{tabular}{lccccccc}
\hline & \multicolumn{3}{c}{ Experienced observers $(\mathrm{n}=3)$} & & \multicolumn{3}{c}{ Inexperienced observers $(\mathrm{n}=3)$} \\
\cline { 2 - 3 } \cline { 7 - 8 } $\begin{array}{l}\text { Observer } \\
\text { comparison }\end{array}$ & $\mathrm{n}$ & $\mathrm{Kw}^{1}$ & $95 \% \mathrm{CI}$ & & $\mathrm{n}$ & $\mathrm{Kw}$ & $95 \% \mathrm{CI}$ \\
\hline 1 and 2 & 219 & 0.67 & $0.60-0.73$ & & 50 & 0.71 & $0.58-0.83$ \\
2 and 3 & 219 & 0.66 & $0.60-0.72$ & & 50 & 0.66 & $0.53-0.79$ \\
1 and 3 & 219 & 0.79 & $0.74-0.83$ & & 50 & 0.69 & $0.59-0.79$ \\
\hline
\end{tabular}

${ }^{1} \mathrm{Kw}=$ weighted kappa. 

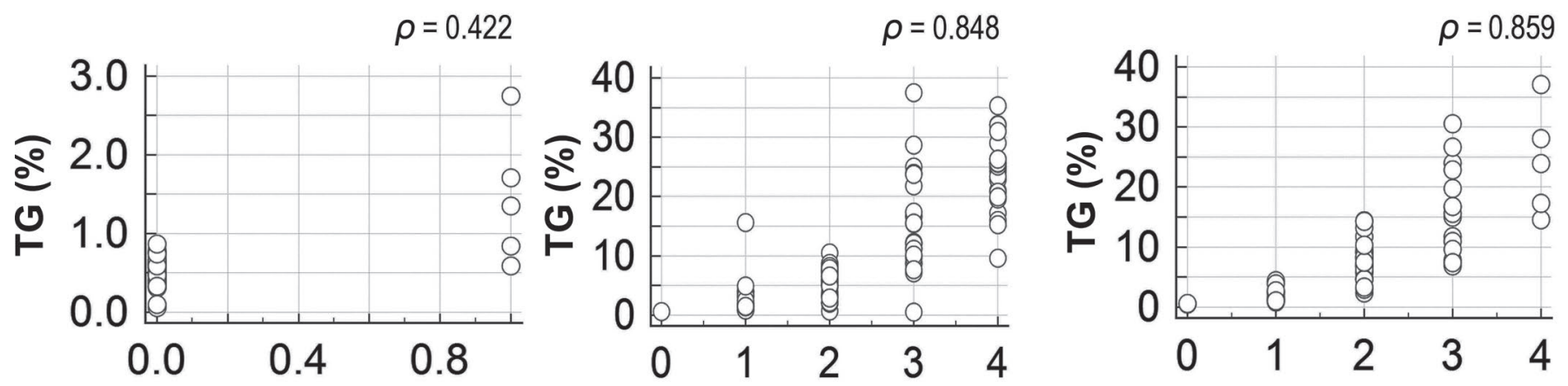

\section{Cytology Score (Median)}

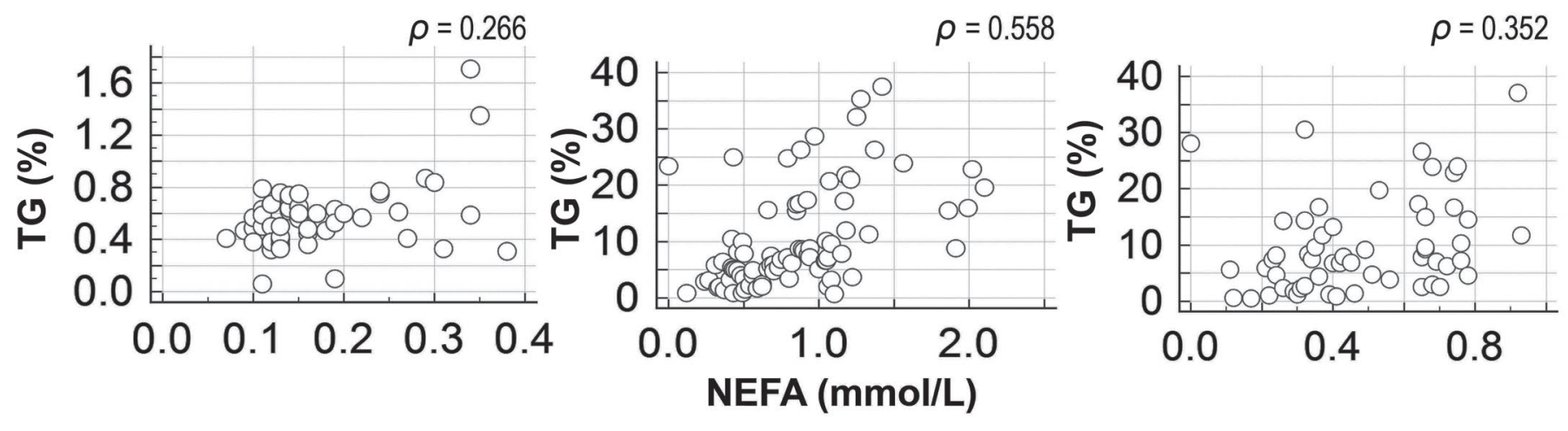

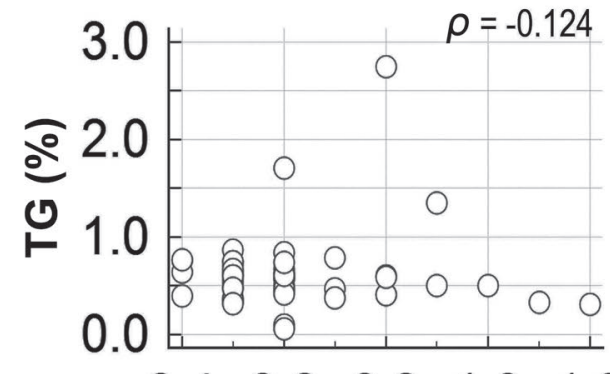

$\begin{array}{lllll}0.4 & 0.6 & 0.8 & 1.0 & 1.2\end{array}$
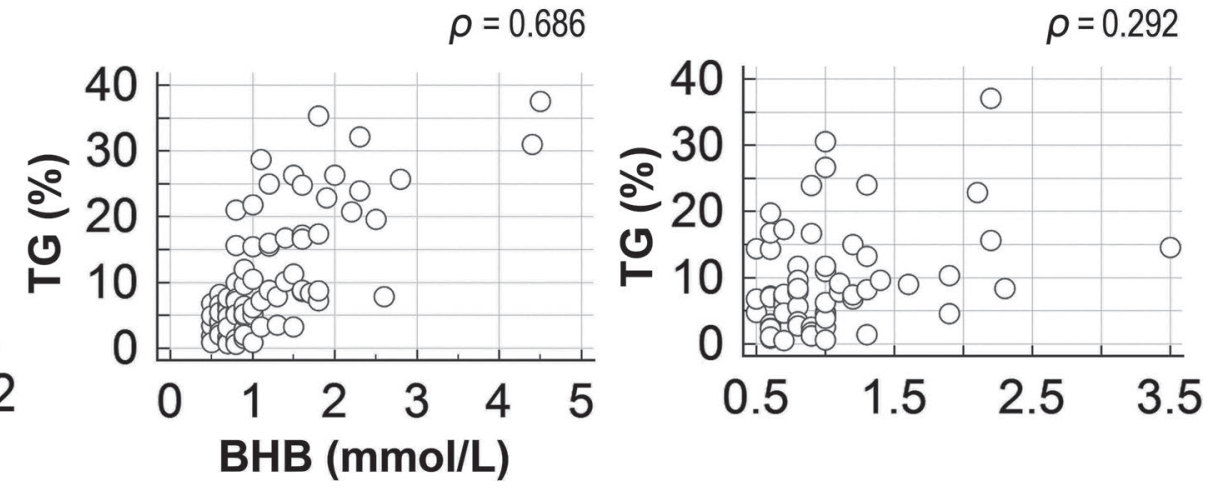

Figure 3. Correlation plots comparing triglyceride percentage $(\mathrm{mg} / \mathrm{mg}$ basis; TG \%) to the median cytology score (row 1), nonesterified fatty acid (NEFA) concentration (row 2), and BHB concentration (row 3), for the 3 groups of cows separated by columns (prepartum -20 to $-2 \mathrm{~d}$ on the left, 1-10 DIM in the middle, and 18-25 DIM on the right). The rho values for each plot are shown in the upper right corner of each graph.

od have been lacking. Based on comparison with "gold standard" quantitative measurement of liver [TG], the results of this study indicate that cytology is an accurate means of detecting HLC in dairy cattle. This conclusion is supported by a strong correlation between blinded, independent cytology scoring and liver [TG], significantly stronger diagnostic performance than plasma NEFA or BHB based on ROC curve analysis at [TG] thresholds representing varying degrees of disease severity, and good interobserver agreement in cytology scoring. Moreover, the strong correlation between liver [TG] and cytology scoring by people with no prior cytology experience and minimal training, and the good interobserver agreement among those people, indicate that veterinarians with no prior experience could easily become competent at evaluating cytology samples for HLC.

There are no universally accepted liver [TG] thresholds for defining degree of HLC or severity of clinical HL in dairy cows. In this study, we used ROC curve 
Table 5. Results of receiver operating characteristic curve analysis comparisons of cytology scoring and plasma nonesterified fatty acids (NEFA) and BHB concentrations, using data stratified by stage of lactation ( 0 to 10 DIM, $\mathrm{n}=80 ; 18$ to 25 DIM, $\mathrm{n}=57$ ) at liver triglyceride concentration [TG] classification thresholds of 5,10 , and $15 \%$

\begin{tabular}{lccc}
\hline & \multicolumn{3}{c}{$\mathrm{AUC}^{1}$} \\
\cline { 2 - 4 } Item & {$[\mathrm{TG}] \geq 5 \%$} & {$[\mathrm{TG}] \geq 10 \%$} & {$[\mathrm{TG}] \geq 15 \%$} \\
\hline Cows 0 to 10 DIM & 0.87 & $0.93^{\mathrm{a}}$ & $0.93^{\mathrm{c}-\mathrm{e}}$ \\
Cytology & 0.77 & $0.80^{\mathrm{b}}$ & $0.82^{\mathrm{d}}$ \\
NEFA & 0.82 & $0.83^{\mathrm{b}}$ & $0.85^{\mathrm{de}}$ \\
BHB & & & \\
Cows 18 to 25 DIM & $0.93^{\mathrm{A}}$ & $0.87^{\mathrm{C}}$ & $0.94^{\mathrm{E}}$ \\
Cytology & $0.65^{\mathrm{B}}$ & $0.73^{\mathrm{D}}$ & $0.74^{\mathrm{F}}$ \\
NEFA & $0.62^{\mathrm{B}}$ & $0.61^{\mathrm{D}}$ & $0.60^{\mathrm{F}}$ \\
BHB &
\end{tabular}

${ }_{\mathrm{a}, \mathrm{b}} \mathrm{AUC}$ within a column that do not share superscripts $\operatorname{differ}(P<$ $0.03)$.

${ }^{\mathrm{ce}} \mathrm{AUC}$ within a column that do not share superscripts differ $(P<$ $0.04)$.

${ }^{\mathrm{A}, \mathrm{B}} \mathrm{AUC}$ within a column that do not share superscripts differ $(P<$ 0.001).

${ }^{\mathrm{C}, \mathrm{D}} \mathrm{AUC}$ within a column that do not share superscripts $\operatorname{differ}(P<$ $0.04)$.

E,F AUC within a column that do not share superscripts differ $(P<$ $0.01)$.

${ }^{1}$ Area under the curve.

analyses thresholds similar to those published previously (Bobe et al., 2004; Haudum et al., 2011). One of the main challenges in assessing the diagnostic utility of tests for HLC or clinical HL is determining the level of liver [TG] that is deleterious not only to hepatocyte function but also to the overall health of the cow. Both NEFA and BHB have deleterious effects on bovine hepatocyte function in vitro (Song et al., 2016), and high serum levels correlate with increased risk of periparturient diseases (Ospina et al., 2010a,b; McArt et al., 2013). However, NEFA and BHB levels do not correlate well with each other and peak levels are highly variable throughout the transition phase (McCarthy et al., 2015). The NEFA-to-cholesterol ratio is reported to be highly predictive of hepatic lipidosis using a liver [TG] of $10 \%$ as a cut off value (AUC: $77 \%$; Mostafavi et al., 2013). Biochemical indicators of hepatocellular injury or dysfunction, such as increases in liver enzyme activities and serum bilirubin concentration, do not correlate with severity of disease and are not specific for lipidosis (Cebra et al., 1997; Kalaitzakis et al., 2007). Serum activity levels of paraxonase-1 (PON-1), an antioxidant carried on high-density lipoproteins, are lower in dairy cows with grossly visible HL (Farid et al., 2013). Additional studies to investigate PON-1 and a more sensitive means of quantifying lipid accumulation in the liver may prove this protein to be clinically useful. A recent study identified a panel of 29 metabolites that showed utility in distinguishing between cows with and without lipidosis using mass spectrometry (Imhasly et al., 2014). Although that study may lead to useful means of detecting HLC and clinical HL in the future, mass spectrometry is not currently diagnostically practical. The threshold amount of lipid accumulation required to cause deleterious effects on hepatocellular function is not known at this time, and likely varies between individual cows.

One limitation of our study was that cytology slides were prepared as touch imprint smears from surgical biopsies, rather than from samples obtained by FNB. Based on our experience (EBK and MMF, boardcertified clinical pathologists with $>20$ yr of combined experience in diagnostic cytopathology), slides prepared from samples obtained by FNB are likely to yield diagnostically comparable results. Moreover, published studies conducted at human medical centers support the use of touch imprint cytology diagnostically (Kubik et al., 2014, 2015). A potential caveat to comparing touch imprint cytology with aspirates would be if the aspirates were obtained with excessive suction or smears prepared using excessive pressure, which could cause cell lysis. This can be avoided by using proper technique but may require practice in the hands of a novice. In a study aimed at evaluating the variability in severity of lipid accumulation across the liver parenchyma, a difference of less than $2 \%$ in [TG] was found between any of 10 sites sampled in the same liver (Gerspach et al., 2017). Another limitation of the study was that temperature extremes of the regional climate might have affected the BHB values: samples were collected over the winter when the average regional temperature is $-4^{\circ} \mathrm{C}$. The meter used in this study is reported to perform optimally in temperatures ranging from 10 to $40^{\circ} \mathrm{C}$.

In the practice setting, diagnosis of HL is usually presumptive. Dairy practitioners rarely submit liver samples for histologic evaluation from cows with suspected HL because of cost and turnaround time constraints, and potential complications from the procedure. Ultrasonography is another method that shows promise as a means of detecting HLC in dairy cattle (Starke et al., 2010; Haudum et al., 2011; Weijers et al., 2012). To our knowledge, no studies to date have directly compared diagnostic performance of cytology and ultrasound for detecting HLC. Correlation between cytology and [TG] in the present study is higher than reported in one study of liver ultrasonography (Bobe et al., 2008). Based on results of ROC curve analysis, at a liver [TG] threshold of $5 \%$, the diagnostic performance of cytology in the present study was similar to that of liver ultrasonography in another study (Weijers et al., 2012). 
Liver FNB is technically feasible in the field setting without the use of ultrasonography, and it is less invasive and less expensive than obtaining a biopsy for histology. Given that the more invasive procedure of obtaining a biopsy for histopathology did not elicit pain-related behavior in dairy cattle in a recent study (Barrett et al., 2016), the FNB procedure is unlikely to cause more than minimal, transient pain. Moreover, samples obtained by FNB can be evaluated cytologically almost immediately after collection by using a rapid Romanowsky-type stain, a diagnostic staple of routine veterinary practice. We purposely use the term "FNB" here instead of fine-needle aspiration because, for many tissue types, a nonaspiration ("pincushion") sampling technique is superior to one that employs suction (LeBlanc et al., 2009).

This study demonstrated that cytology can predict liver [TG] and does so more accurately than plasma [NEFA] or $[\mathrm{BHB}]$. These findings support continued investigation of FNB liver cytology as a practical, minimally invasive addition to the diagnostic toolkit for veterinary dairy herd health management, particularly with regard to HL. Additional study would be required to determine more specifically how cytologic detection of HLC relates to clinicoeconomically relevant consequences of HL-including clinical disease, diminished response to therapy, and decreased productivity - and to determine whether we can develop good guidelines for using cytology to inform clinical decision-making. Liver cytology could potentially be helpful in diagnosing other conditions, such as hepatic lipodystrophy that has been documented in Galloway calves. Affected calves consistently show marked accumulations of lipid on histopathological examination of tissues collected at necropsy. The high levels of lipid would likely be easily detected by an aspirate and provide more specific support as to the underlying etiology antemortem than the nonspecific plasma biochemical markers that have been associated with the degree of hepatic lipodystrophy postmortem (Wieland et al., 2017). Further studies are planned to assess the clinical utility of FNB liver cytology for diagnosis of HL in dairy cattle.

\section{ACKNOWLEDGMENTS}

This work was supported in part by a grant from the Office of Research, University of Tennessee College of Veterinary Medicine. The authors gratefully acknowledge Xiaojuan Zhu (Office of Information Technology Research Computing Support, University of Tennessee) for statistical consultation. Preliminary results of this study were presented as an oral abstract at the Annual Meeting of the American Society for Veterinary Clinical Pathology in December 2016 (New Orleans, LA).

\section{REFERENCES}

Arndt, T. P., and S. M. Shelly. 2014. The liver. Pages 317-319 in Cowell and Tyler's Diagnostic Cytology and Hematology of the Dog and Cat. 3rd ed. A. C. Valenciano and R. L. Cowell, ed. Mosby Elsevier, St. Louis, MO.

Bach, K. D., W. Heuwieser, and J. A. McArt. 2016. Technical note: Comparison of 4 electronic handheld meters for diagnosing hyperketonemia in dairy cows. J. Dairy Sci. 99:9136-9142.

Barger, A. M., and A. L. MacNeill. 2016. Liver cytology. Pages 246247 in Small Animal Cytologic Diagnosis. 1st ed. CRC Press Taylor and Francis Group, Boca Raton, FL.

Barrett, L. A., N. J. Beausoleil, J. Benschop, and K. J. Stafford. 2016. Pain-related behavior was not observed in dairy cattle in the days after liver biopsy, regardless of whether NSAIDs were administered. Res. Vet. Sci. 104:195-199.

Bobe, G., V. R. Amin, A. R. Hippen, P. She, J. W. Young, and D. C. Beitz. 2008. Non-invasive detection of fatty liver in dairy cows by digital analyses of hepatic ultrasonograms. J. Dairy Res. 75:84-89.

Bobe, G., J. Young, and D. Beitz. 2004. Invited review: Pathology, etiology, prevention, and treatment of fatty liver in dairy cows. J. Dairy Sci. 87:3105-3124.

Cebra, C. K., F. Garry, D. Getzy, and M. Fettman. 1997. Hepatic lipidosis in anorectic, lactating Holstein cattle: A retrospective study of serum biochemical abnormalities. J. Vet. Intern. Med. 11:231-237.

Farid, A. S., K. Honkawa, E. M. Fath, N. Nonaka, and Y. Horii. 2013. Serum paraoxonase-1 as biomarker for improved diagnosis of fatty liver in dairy cows. BMC Vet. Res. 9:73-84.

Folch, J., M. Lees, and G. H. Sloane Stanley. 1957. A simple method for the isolation and purification of total lipids from animal tissues. J. Biol. Chem. 226:497-509.

Gaal, T., I. Reid, R. Collins, C. Roberts, and B. Pike. 1983. Comparison of biochemical and histological methods of estimating fat content of liver of dairy cows. Res. Vet. Sci. 34:245-248.

Gerspach, C., S. Imhasly, R. Klingler, M. Hilbe, S. Hartnack, and M. Ruetten. 2017. Variation in fat content between liver lobes and comparison with histopathological scores in dairy cows with fatty liver. BMC Vet. Res. 13:98-109.

Haudum, A., A. Starke, M. Beyerbach, P. Wohlsein, and J. Rehage. 2011. Ultrasonographic assessment of liver dimensions in dairy cows with different hepatic triacylglycerol content. J. Anim. Sci. 89:1392-1400

Herdt, T. H. 1988. Fatty liver in dairy cows. Vet. Clin. North Am. Food Anim. Pract. 4:269-287.

Hoff, B., and J. Cote. 1996. Fine needle aspiration and liver cytology-A simple method for diagnosis and prognosis of fatty liver in cattle. Bovine Pract. 30:53-55.

Holtenius, P. 1961. Cytological puncture. A new method for the study of bovine hepatic disease. Cornell Vet. 51:56-63.

Holtenius, P., O. Knudsen, and L.-E. Ullberg. 1962. Cytological studies of the liver in cows with puerperal paresis. Cornell Vet. 52:185191.

Hughes, J. P. 1962. A simplified instrument for obtaining liver biopsies in cattle. Am. J. Vet. Res. 23:1111-1113.

Imhasly, S., H. Naegeli, S. Baumann, M. von Bergen, A. Luch, H. Jungnickel, S. Potratz, and C. Gerspach. 2014. Metabolomic biomarkers correlating with hepatic lipidosis in dairy cows. BMC Vet. Res. 10:122.

Kalaitzakis, E., N. Roubies, N. Panousis, K. Pourliotis, E. Kaldrymidou, and H. Karatzias. 2007. Clinicopathologic evaluation of hepatic lipidosis in periparturient dairy cattle. J. Vet. Intern. Med. 21:835-845.

Kubik, M. J., A. Bovbel, H. Goli, J. Saremian, A. Siddiqi, and S. Masood. 2015. Diagnostic value and accuracy of imprint cytology evaluation during image-guided core needle biopsies: Review of our experience at a large academic center. Diagn. Cytopathol. 43:773-779.

Kubik, M. J., A. Mohammadi, and M. Rosa. 2014. Diagnostic benefits and cost-effectiveness of on-site imprint cytology adequacy evaluation of core needle biopsies of bone lesions. Diagn. Cytopathol. 42:506-513. 
Leblanc, C. J., L. L. Head, and M. M. Fry. 2009. Comparison of aspiration and nonaspiration techniques for obtaining cytologic samples from the canine and feline spleen. Vet. Clin. Pathol. 38:242-246.

Mann, S., F. A. L. Yepes, T. R. Overton, J. J. Wakshlag, A. L. Lock, C. M. Ryan, and D. V. Nydam. 2015. Dry period plane of energy: Effects on feed intake, energy balance, milk production, and composition in transition dairy cows. J. Dairy Sci. 98:3366-3382.

McArt, J. A., D. V. Nydam, and G. R. Oetzel. 2012. Epidemiology of subclinical ketosis in early lactation dairy cattle. J. Dairy Sci. 95:5056-5066.

McArt, J. A., D. V. Nydam, G. R. Oetzel, T. R. Overton, and P. A. Ospina. 2013. Elevated non-esterified fatty acids and $\beta$-hydroxybutyrate and their association with transition dairy cow performance. Vet. J. 198:560-570.

McCarthy, M. M., S. Mann, D. V. Nydam, T. R. Overton, and J. A. McArt. 2015. Short communication: concentrations of nonesterified fatty acids and $\beta$-hydroxybutyrate in dairy cows are not well correlated during the transition period. J. Dairy Sci. 98:6284-6290.

Meyer, D. M. 2016. The liver. Pages 259-270 in Canine and Feline Cytology: A Color Atlas and Interpretation Guide. 4 ed. R. E. Raskin and D. J. Meyer, ed. Elsevier, St. Louis, MO.

Mostafavi, M., H. Seifi, M. Mohri, and A. Jamshidi. 2013. Optimal thresholds of metabolic indicators of hepatic lipidosis in dairy cows. Rev. Med. Vet. (Toulouse) 164:564-571.

Ospina, P. A., D. V. Nydam, T. Stokol, and T. R. Overton. 2010a Associations of elevated nonesterified fatty acids and beta-hydroxybutyrate concentrations with early lactation reproductive performance and milk production in transition dairy cattle in the northeastern United States. J. Dairy Sci. 93:1596-1603.

Ospina, P. A., D. V. Nydam, T. Stokol, and T. R. Overton. 2010b. Evaluation of nonesterified fatty acids and beta-hydroxybutyr- ate in transition dairy cattle in the northeastern United States: Critical thresholds for prediction of clinical diseases. J. Dairy Sci. 93:546-554.

Ríos, C., M. M. Fry, C. N. Grimes, L. E. Craig, and P. Melendez. 2013. Comparación de citología mediante aspirado de aguja fina e histología en el diagnóstico delipidosis hepática en bovinos de matadero. Av. Cienc. Vet. 28:13-18.

Ríos, C. L., M. M. Fry, C. N. Grimes, L. E. Craig, and P. Melendez. 2010. Preliminary assessment of fine-needle aspiration cytology to diagnose bovine hepatic lipidosis. Abstr. 16 in Proc. XIVth Congress, International Society of Animal Clinical Pathology, Corvallis, OR. Vet. Clin. Pathol. 39:520-533.

Song, Y., N. Li, J. Gu, S. Fu, Z. Peng, C. Zhao, Y. Zhang, X. Li, Z Wang, and G. Liu. 2016. $\beta$-Hydroxybutyrate induces bovine hepatocyte apoptosis via an ROS-p38 signaling pathway. J. Dairy Sci. 99:9184-9198

Starke, A., A. Haudum, G. Weijers, K. Herzog, P. Wohlsein, M. Beyerbach, C. L. de Korte, J. M. Thijssen, and J. Rehage. 2010. Noninvasive detection of hepatic lipidosis in dairy cows with calibrated ultrasonographic image analysis. J. Dairy Sci. 93:2952-2965.

Veenhuizen, J. J., J. K. Drackley, M. J. Richard, T. P. Sanderson, L. D. Miller, and J. W. Young. 1991. Metabolic changes in blood and liver during development and early treatment of experimental fatty liver and ketosis in cows. J. Dairy Sci. 74:4238-4253.

Weijers, G., A. Starke, J. M. Thijssen, A. Haudum, P. Wohlsein, J. Rehage, and C. L. de Korte. 2012. Transcutaneous vs. intraoperative quantitative ultrasound for staging bovine hepatic steatosis. Ultrasound Med. Biol. 38:1404-1413.

Wieland, M., S. Mann, A. Hafner-Marx, A. Ignatius, and M. Metzner. 2017. Hepatic lipodystrophy in Galloway calves. Vet. Pathol. $54: 464-474$ 